\title{
LITERATURA COMO TECNOLOGIA DE GÊNERO: REPRESENTAÇÕES ALTERNATIVAS DE MULHER POR ESCRITORAS INGLESAS NO SÉCULO XIX
}

\author{
Literature as a technology of gender: alternative representations of women \\ by English women writers in the nineteenth century
}

\author{
Daiane da Silva LOURENÇO \\ Universidade Tecnológica Federal do Paraná \\ daianelourenco@utfpr.edu.br \\ https://orcid.org/0000-0002-4710-7580
}

\begin{abstract}
RESUMO: No início do século XIX, na Inglaterra, as mulheres estavam sob rígidas convenções de gênero. A educação feminina era voltada a preparar as jovens para atenderem a um ideal de mulher normalizado. Apesar das barreiras existentes devido aos padrões de gênero, escritoras publicaram romances focados em experiências femininas.Este artigo discute como essas obras são tecnologias de gênero que contribuíram para (re)construir as identidades de leitoras. A partir da crítica feminista e dos estudos culturais, representações de mulheres em Orgulho $e$ Preconceito (1813), de Jane Austen, são analisadas. A análise revela que através de estratégias de escrita presentes no texto literário a educação feminina e o ideal de mulher são questionados. O comportamento "desviante" de Elizabeth Bennet é usado para desestabilizar a feminilidade hegemônica. Na época de publicação do romance, a personagem, como representação de sujeito, inseriu formas alternativas de ser mulher no imaginário social que podem ter influenciado a identidade de leitoras.
\end{abstract}

PALAVRAS-CHAVE: Representação; Tecnologia de Gênero; Identidade; Personagens Femininas.

\begin{abstract}
Women were under strict gender roles in England at the beginning of the nineteenth century. The education of women was centered on preparing girls to achieve a true lady ideal standard. Despite existing barriers due to gender norms, women writers published novels about female life experiences. This paper discusses how those novels are examples of gender technologies that have contributed to (re)constructing the identities of women readers. Based on feminist criticism and cultural studies, representations of women are analyzed in Pride and Prejudice (1813), by Jane Austen. The analysis reveals that, through writing strategies in the literary text, female education and the true lady ideal are contested. The "deviant" behavior of Elizabeth Bennet is used to destabilize hegemonic femininity. At the time of publication of the novel, that character, a representation of subject, inserted alternative
\end{abstract}


forms of being a woman in the social imaginary that could have had an impact on women readers identities.

KEYWORDS: Representation; Gender Technology; Identity; Female Characters.

\section{INTRODUÇÃO}

A literatura de autoria feminina inglesa do século XIX foi produzida por escritoras que superaram barreiras de gênero que existiam na época. Neste momento histórico, a escrita era considerada uma atividade essencialmente masculina. A caneta literária esteve por muito tempo nas mãos masculinas, as quais construíram representações de mulheres em textos durante séculos. Jane Austen, Charlotte Brontë, Emily Brontë e George Eliot são algumas escritoras precursoras na literatura que apresentaram ao mundo personagens femininas criadas por mulheres neste período.

Uma análise de tais obras desde a perspectiva da crítica feminista lança luz aos sentidos construídos pelas escritoras e revela como eram os papéis de gênero naquele contexto e as concepções de feminilidade ${ }^{1}$, muitas das quais ainda propagadas na sociedade ocidental contemporânea.Da perspectiva dos estudos culturais, por sua vez, pesquisas questionam conceitos consolidados, abordam a desestabilização das noções de identidade do sujeito e o poder da representação. Neste trabalho, os estudos culturais se intersectam com estudos de gênero no campo da literatura. Por meio de uma análise interpretativa, olhamos para as imagens de mulheres inseridas no romance Orgulho $e$ Preconceito (1813), de Jane Austen.

A literatura é vista nesta pesquisa como uma tecnologia de gênero que produz e promove representações de mulheres, modela opiniões e comportamentos, fornece material que pode influenciar de forma direta ou indireta as identidades de leitoras através dos discursos que propaga. As representações de sujeito no romance podem contribuir com a construção de subjetividades de leitoras que, no contato com a literatura, adquirem

\footnotetext{
${ }^{1}$ A feminilidade é uma construção social, cultural e histórica de naturalização de papéis sociais e de comportamentos atribuídos às mulheres. As convenções de gênero não são naturais, mas uma constituição simbólica que resulta de processos de opressão e de hierarquização de diferenças entre masculino e feminino (CAMPOS, 1992). Diante disso, a feminilidade costuma ser associada a características esperadas das mulheres, como ser frágil, dócil, sensível, altruísta, cuidar da beleza, entre outras. Além dessas características, no início do século XIX, existiam expectativas sociais rígidas na Inglaterra sobre como as mulheres deveriam comportar-se em público, o que incluía não expressar suas opiniões, por exemplo. Essas
} 
valores e opiniões que enriquecem sua visão do mundo.O romance Orgulho e Preconceito promoveu, na época de sua publicação, representações alternativas de mulher em um contexto social caracterizado por uma cultura patriarcal arraigada.

Nesse sentido, a primeira seção deste artigo introduz a situação social das mulheres na Inglaterra do início do século XIX e explora o ideal de feminilidade. A educação feminina e o casamento como propósito de vida das jovens são discutidos apresentando percepções de mulheres escritoras da época, Mary Wollstonecraft e Frances Power Cobbe. Na seção seguinte, a literatura de autoria feminina é abordada como uma tecnologia de gênero. A ascensão do romance como gênero literário endereçado ao público feminino contribuiu para que, apesar da repressão social, diversas escritoras registrassem suas obras como forma de autoexpressão e com o intuito de falar sobre as experiências de mulheres.Para tanto, utilizaram estratégias de escrita e, até mesmo, omitiram seus nomes ou usaram pseudônimos masculinos.

A terceira seção apresenta uma análise de personagens femininas de Orgulho $e$ Preconceito. Elizabeth Bennet é apontada como uma personagem com atitudes subversivas. A forma como Jane Austen construiu a narrativa coloca tal personagem em evidência, em detrimento de outras que atendiam ao ideal de mulher estabelecido, o que revela uma intenção de desestabilizar o padrão hegemônico de feminilidade. Além disso, a partir dos estudos culturais, discutimos como a personagem é uma representação, construção de sentido que insere formas alternativas de ser mulher no imaginário social.

\section{O IDEAL DE MULHER}

No início do século XIX, na Inglaterra, havia um ideal estabelecido sobre ser mulher, principalmente para aquelas que pertenciam a classes sociais de maior status, denominadas, na época, gentry e aristocracia. A concepção de que as mulheres deveriam ser proper ladies estava enraizada na sociedade britânica. As mulheres eram preparadas desde crianças para desenvolverem habilidades e talentos específicos para serem esposas e mães. A educação feminina era centrada no espaço privado, na vida doméstica, e normalmente as meninas não tinham acesso ao ensino formal em uma escola.

expectativas são abordadas ao longo do artigo. 
Teachman (1997) explica que em todos os níveis sociais da Inglaterra a educação formal das filhas era considerada menos importante que a dos filhos. Essa cultura patriarcal predominava em um momento histórico no qual as mulheres inglesas eram privadas de direitos civis e políticos. De modo geral, as jovens não tinham acesso a uma educação formal, enquanto a maioria dos filhos da classe alta eram educados em escolas de qualidade e frequentavam a universidade com o objetivo de se prepararem para uma carreira e o convívio com outros homens da mesma classe social.

Como a educação feminina não era considerada tão relevante para preparar uma mulher para a vida adulta, Teachman (1997) relata que as jovens de classe alta eram educadas em casa pela mãe, por uma governanta ou uma tutora. As meninas aprendiam a ler e a fazer cálculos básicos para organizar as contas da casa, porém a maior parte de sua educação era voltada para habilidades como tocar piano, cantar, bordar, dançar, desenhar e pintar. Já as mulheres de classe baixa aprendiam o básico sobre tarefas domésticas, incluindo costurar e cozinhar, e também sobre decoração da casa com poucos recursos a fim de terem a possibilidade de se casar com homens com pequeno patrimônio ou de trabalhar como criadas.

A partir da observação dessa realidade, Mary Wollstonecraft, na obra Reivindicação dos direitos da mulher (1792), denuncia como a falta de acesso à educação formal e a reclusão da mulher à vida doméstica a tornam dependente dos homens (pai, irmão, marido). Para a autora, as mulheres

"[...] passam grande parte dos primeiros anos de vida adquirindo habilidades superficiais; enquanto isso, a força do corpo e da mente é sacrificada em nome de noções libertinas de beleza e do desejo de se estabelecer mediante o matrimônio [...]" (WOLLSTONECRAFT, 2016, p. 28).

Além disso, critica como “[...]os homens na juventude são preparados para as profissões, e o casamento não é considerado o grande feito de sua vida; enquanto as mulheres, ao contrário, não têm outro projeto para aguçar as faculdades" (WOLLSTONECRAFT, 2016, p. 86). A tese defendida na obra é a de que as mulheres, assim como os homens, deveriam ter direito à educação formal e, como resultado, a educação lhes daria independência e não se casariam com o único objetivo de ter um 
sustento. A fragilidade, apontada como característica feminina, é abordada como um aspecto que não é natural das mulheres, mas desenvolvido nas jovens e alimentado ao longo de suas vidas por falta de uma educação intelectual apropriada.

Essas breves exposições sobre o contexto do início do século XIX revelam como as expectativas sociais eram distintas para homens e para mulheres. Aqueles eram preparados para atuar no espaço público enquanto o universo doméstico era reservado para as mulheres. De acordo com Wollstonecraft (2016), somente o acesso à educação formal permitiria uma mudança no papel social da mulher, fazendo com que a mulher não fosse incentivada a casar para ter estabilidade financeira e permitindo que ficasse solteira, se assim preferisse, com maiores possibilidades de emprego, pois até então as opções consideradas respeitáveis para mulheres que precisavam trabalhar eram restritas principalmente a serem governantas ou professoras, profissões que lhes garantiam remunerações baixas. A percepção de Wollstonecraft é de que as mulheres tinham capacidade intelectual para fazer mais na sociedade e poderiam atuar como médicas, administrar fazendas, gerenciar comércios, enfim, ter uma formação superior. Apesar da luta da autora pela emancipação feminina, seguida por reivindicações de outras mulheres no século XIX, somente na década de 1860 as mulheres inglesas conseguiram o direito de frequentar o ensino superior.

As restrições sociais faziam com que as mulheres fossem instruídas desde crianças a conseguirem um casamento rentável, pois era a principal forma de assegurar uma renda anual. No entanto, a seguridade financeira por meio do casamento transformava a mulher em propriedade do homem. De acordo com Teachman (1997), baseado na lei de coverture, após o casamento, o homem e a mulher se tornavam uma pessoa: o marido. Teachman (1997) explica que tal lei estabelecia que a identidade independente da mulher, de solteira, praticamente deixaria de existir no casamento porque qualquer ação da esposa só poderia efetivamente ser realizada com o consentimento do marido. Portanto, as leis vigentes faziam com que a mulher fosse vista como uma propriedade masculina: primeiro do pai, depois do marido. A mulher solteira era conhecida na sociedade pelo sobrenome do pai (Miss Bennet, por exemplo) e a casada pelo sobrenome do marido (Mrs. Darcy), sem uma identidade própria.

Apesar de o casamento ser o objetivo principal da vida da maioria das mulheres da 
época, tal como retratado nas obras de Jane Austen, o matrimônio era de fato vantajoso para os homens. Sir William Blackstone, em Commentaries on the laws of England, publicado em 1765, descreve os direitos do marido e da esposa dentro da common law (direito comum) na Inglaterra. O marido tem controle legal e econômico sobre a mulher. A mulher não é considerada uma pessoa perante a lei, por isso não pode possuir bens, tomar decisões sobre os filhos, os quais são considerados do marido, assinar documentos ou contratos, ter uma renda própria ou acessar qualquer tipo de educação sem a permissão do companheiro. Toda atividade social da esposa deve ser realizada utilizando o nome do marido. Por causa desse entendimento legal, após o casamento os bens da mulher eram transformados em posses do homem, de modo que mulheres casadas não tinham qualquer espécie de rendimento particular.

O cenário descrito revela que a estabilidade financeira e social da mulher dependia do marido. Teachman (1997) ressalta que a inclinação e caráter do homem escolhido para casar, assim como sua capacidade de sustentar a esposa, eram de interesse das mulheres para a garantia de um casamento tranquilo. Essa segurança era primordial, porque, caso a mulher sofresse qualquer tipo de dano moral ou físico, não conseguiria processar o marido, já que perante a lei não tinha identidade. Um casamento sem sucesso significava a desgraça da mulher uma vez que não tinha recursos próprios, não conseguia trabalhar sem permissão do marido e não podia deixar a casa levando os filhos, os quais não lhes pertenciam legalmente. Além disso, caso a mulher conseguisse trabalhar, sua remuneração era assegurada ao marido.

As circunstâncias relatadas sobre a vida das mulheres começariam a mudar apenas no final do século XIX. Frances Power Cobbe, no texto A discussion on the laws concerning the property of married women, publicado em 1869, critica como a lei do direito comum falha em assegurar justiça para as mulheres casadas. No texto, cita exemplos de casos de esposas que tentaram conseguir o divórcio, assegurar o direito à sua remuneração, garantir a guarda dos filhos, mas tiveram seus pedidos recusados pela justiça, que defende os direitos dos maridos. Diante disso, questiona se o que é posto como relacionamento perfeito não deveria ser chamado de dependência perfeita. Para Cobbe, a lei do direito comum da Inglaterra existe para que os homens assegurem seus próprios direitos. Em suma, afirma que não é uma lei justa, pois não protege ou sequer faz um 
esforço para proteger as mulheres que são forçadas a renunciarem aos bens quando se casam.

Somente em 1882, com a aprovação do Married Women's Property Act, as mulheres casadas adquirem o direito de serem proprietárias legais do dinheiro que ganham, de herdarem e controlarem bens. Além disso, a lei tornou ambos os pais igualmente responsáveis pelos filhos. Essas mudanças aumentaram a autonomia das mulheres casadas, as quais passaram a ter uma identidade perante a lei. Neste contexto, alguns direitos civis haviam sido conquistados pelas mulheres. O direito ao voto, no entanto, só seria alcançado em 1919.

Esse breve olhar para a história das mulheres na Inglaterra objetiva demonstrar como viviam sob diversas restrições econômicas, sociais e morais. No início do século XIX, espaços distintos eram estabelecidos para os gêneros: a vida pública para os homens, seja trabalhando ou socializando em reuniões, festas, clubes; e a esfera privada e doméstica para as mulheres, as quais ocupavam o tempo cuidando da casa e da família. Além das habilidades domésticas, as mulheres aprendiam desde a infância a se comportar de modo apropriado na sociedade, a respeitar os ensinamentos morais e a se vestir adequadamente para sair em público. Em resumo, eram educadas para atender às imposições da sociedade para serem qualificadas como uma proper lady, o ideal de mulher propagado.

Na segunda metade do século XVIII, textos sobre a conduta feminina ganharam volume e popularidade por causa da importância dada à educação doméstica e do aumento significativo do número de leitoras da classe média (POOVEY, 1984). Os chamados conduct books, livros de conduta, tinham como objetivo instruir as mulheres sobre como comportar-se para serem consideradas virtuosas pela sociedade. Evidentemente, os valores ensinados nas obras baseavam-se na ideologia cultural do período. Importante destacar que muitas dessas obras eram assinadas por homens, autores que demonstravam preocupação com o cultivo constante das virtudes femininas. Wollstonecraft (2016) critica como os livros de conduta afirmam que as mulheres respeitáveis são modestas, gentis, dóceis, frágeis, sensíveis e emotivas, e tais características são tratadas como naturalmente femininas. Para a autora, esses textos contribuem para promover tais atributos como ideal de feminilidade: 
Os moralistas permitem aos homens cultivar, como manda a Natureza, diferentes qualidades e assumir os diversos aspectos que as mesmas paixões, modificadas quase ao infinito, dão a cada indivíduo. Um homem virtuoso pode ter uma constituição colérica ou otimista, ser alegre ou sério, sem ser reprovado; ser firme o mais que puder ou tão dócil que não tenha vontade ou opinião própria; mas todas as mulheres têm de ajustar-se, por meio da mansidão e da docilidade, a um mesmo caráter de doçura condescendente e de amável submissão (WOLLSTONECRAFT, 2016, p. 126-127).

As diferentes concepções de virtude para o homem e para a mulher são questionadas no trecho citado com a intenção de ressaltar como o julgamento da sociedade é distinto de acordo com o gênero. Wollstonecraft (2016) mostra que os homens buscam nas mulheres a beleza, a docilidade e o bom humor e rejeitam a razão. Por isso, os livros de conduta orientam as jovens a evitar expressar suas opiniões em público, como no trecho de A father's legacy to his daughters, publicado por John Gregory em 1808:

Sejam sempre prudentes para demonstrar seu bom senso. Não deixem que se pense que estão assumindo certa superioridade sobre os demais. Mas se, por acaso, tiverem algum conhecimento, guardem-no como um segredo profundo, especialmente dos homens, que em geral veem com um olhar ciumento e maléfico uma mulher de grande talento e inteligência desenvolvida (WOLLSTONECRAFT, 2016, p. 129-130).

Essa regra de conduta é colocada como um conselho de um pai para suas filhas, revelando um contexto em que a modéstia feminina atrai aos homens. No entanto, evidencia a negação da razão para as mulheres, as quais são instruídas a não opinarem, não questionarem e não cultivarem a mente, pois o exercício da mente é visto como atividade essencialmente masculina. A relevância histórica da perspectiva de Wollstonecraft (2016) está no fato de ser uma das primeiras autoras a demonstrar como o ideal de feminilidade prescrito para as jovens da época, principalmente nos livros de conduta, não é natural. Wollstonecraft (2016) mostra que essas condutas femininas são ensinadas às meninas desde cedo para que as assimilem culturalmente e as aceitem como uma verdade incontestável.

A partir dessas proposições, é possível afirmar que o ideal de feminilidade do início do século XIX, na Inglaterra, determinava que as mulheres fossem modestas. Segundo Poovey (1984), os homens eram assertivos e expressavam suas opiniões em 
público, por isso as mulheres deveriam agir de forma oposta, ou seja, concordar com eles e preferir o silêncio, como demonstração de modéstia e uma atitude feminina "natural". Essa imagem ideal de mulher propagada na época é apontada por Poovey (1984) como um estereótipo de feminilidade reducionista que tornava um "monstro" qualquer mulher que tinha uma conduta fora dos padrões estabelecidos, como demonstrar seu conhecimento. $\mathrm{O}$ simples ato de expressar-se publicamente era considerado uma afronta às condutas esperadas de mulheres respeitáveis. Com base nesse contexto, discutimos, na próxima seção,as diversas barreiras sociais, culturais e econômicas enfrentadas por escritoras, mulheres que agiram em desacordo com os padrões de feminilidade.

\section{LITERATURA DE AUTORIA FEMININA COMO TECNOLOGIA DE GÊNERO}

Se a modéstia era considerada a principal virtude de uma mulher, publicar uma obra era um ato de exposição pública que colocava em risco a reputação da escritora. Ainda assim, havia mulheres que encontravam formas de superar as barreiras e registravam suas produções escritas. Essas atividades subversivas revelam que, apesar de submetidas às rígidas convenções sociais, as mulheres mantinham desejos e interesses próprios, ou seja, agiam de maneira dúbia para não serem julgadas negativamente. Diante das restrições enfrentadas na sociedade, a escrita literária foi uma forma encontrada pelas mulheres para dizerem o que pensavam por vias indiretas, pois podiam usar o argumento de que sua obra é uma ficção.

Como a escrita era considerada uma atividade essencialmente masculina, Poovey (1984) afirma que o simples ato de escrever já era uma estratégia importante de resistência e uma tentativa de subjetificação das mulheres. Também destaca que o grande legado literário desse período é o repertório de estratégias que permitia às escritoras que se expressassem em um código que pode ser interpretado de duas maneiras: como aceitação das normas e como desvio. O foco do romance no espaço doméstico e em histórias de amor permitiu que escritoras o adotassem como gênero literário fundamental para falar sobre as experiências de mulheres. Através dele, abordavam aspectos ordinários, considerados menores comparados às discussões masculinas, transformando-os em significativos por meio da linguagem literária. De acordo com Poovey (1984), as mulheres abordavam a passividade, a abnegação e a resignação femininas de modo heroico fazendo 
o uso de estratégias de escrita.

As escritoras utilizavam o texto como forma de autoexpressão, porém por vias indiretas. Poovey (1984) ressalta que os comportamentos contraditórios que desenvolviam no cotidiano eram retratados pelas escritoras nos romances através da linguagem ambígua, velada e dual. A técnica de "duplicar" as personagens femininas é usada por muitas escritoras da época. Segundo Poovey (1984), é uma forma de apresentar facetas femininas opostas construindo uma personagem resignada e outra inconformada, uma criada obediente e uma jovem afortunada, uma personagem que é o oposto da heroína com qualidades perfeitas para abordar atitudes que eram proibidas e inapropriadas para mulheres de respeito. Essas técnicas inseriam nos textos personagens femininas que fugiam dos estereótipos de mulher até então popularizados por escritores.

As mulheres não tinham direito garantido de acesso a uma educação formal nem podiam integrar grupos que debatiam política, filosofia e literatura, pois não eram espaços considerados femininos, então utilizaram o romance como forma de expressar seu descontentamento com o papel social estabelecido para a mulher da época. Vasconcelos (2016) ressalta que algumas arriscaram e enfrentaram o julgamento social, muitas vezes anonimamente, ingressando em um espaço majoritariamente masculino. A literatura possibilitava que mulheres escondessem a identidade, se assim preferissem, e se esquivassem dizendo que não se tratava de uma discussão séria, mas sim de ficção. Diante das condições adversas que tiveram de suportar, Vasconcelos (2016) afirma que é um fato notável a ousadia das escritoras inglesas dos séculos XVIII e XIX, as quais “[...] na sua busca por uma voz pública, ajudaram a forjar as convenções do romance, criando uma tradição do romance feminino" (VASCONCELOS, 2016, p. 105).

Em períodos anteriores, mulheres arriscaram escrever gêneros consolidados, como poesia e drama (Aphra Behn no século XVII, por exemplo). No século XIX, no entanto, muitas escolheram o romance para iniciarem suas carreiras como escritoras literárias porque ainda era um gênero novo na época, podendo ser moldado, e era voltado ao público feminino. A escritora Virginia Woolf (2014) explica que as formas antigas de literatura já estavam estabelecidas no momento em que as mulheres começaram a ingressar nessa carreira, "apenas o romance era jovem o bastante para ser suavizado em suas mãos" (WOOLF, 2014, p. 111). Além desse motivo, Poovey (1984) considera que o 
romance sentimental, popularizado principalmente por Richardson no final do século XVIII, tinha as características necessárias para as mulheres abordarem suas experiências, pois era focado no universo doméstico e em questões sentimentais e pessoais.

Periódicos, revistas femininas e romances foram utilizados por escritoras como formas de registrar narrativas da perspectiva feminina, pois por muito tempo as mulheres foram representadas a partir do olhar masculino. De acordo com Showalter (1977), nesse momento, as escritoras estavam procurando aprender com modelos de escrita para iniciarem uma construção de representação de mulher do ponto de vista feminino. Para tanto,no começo, utilizaram a imitação da tradição de escrita masculina dominante, perpetuando os padrões de arte e as representações dos papéis sociais no texto. A tradição literária feminina originou-se de leituras de escritores, mas, ao longo do caminho, as escritoras viram nos textos a possibilidade de reconstruírem as representações de mulheres presentes nos livros da época.

A caneta literária esteve por muito tempo nas mãos de homens. De acordo com Gilbert e Gubar (2000), a caneta era considerada essencialmente uma "ferramenta masculina", logo, inapropriada para as mulheres. As autoras explicam que, no início do século XIX, uma mulher dedicada à escrita era julgada socialmente como anormal e "não feminina". O "normal" na sociedade patriarcal era que homens criassem personagens femininas e retratassem mulheres a partir de suas perspectivas, as quais usualmente revelavam imagens de mulheres anjos ou monstros. Apesar disso, Gilbert e Gubar (2000) afirmam que, no final do século XVIII, mulheres estavam escrevendo e revisando as convenções patriarcais em seus textos. O principal obstáculo enfrentado pelas escritoras era o gênero, por serem mulheres eram consideradas inadequadas e não femininas, inferiorizadas por sua criatividade, definidas como solitárias e loucas. Diante disso, algumas decidiram usar pseudônimos masculinos para publicar, como George Eliot (Mary Ann Evans), Currer Bell (Charlotte Brontë), Ellis Bell (Emily Brontë) e Acton Bell (Anne Brontë), ou omitir o nome na capa da obra, como Jane Austen ao identificar-se como "a lady".

As escritoras citadas são importantes para a história da literatura de autoria feminina por terem iniciado o trabalho de revisar, desconstruir e reconstruir as imagens de mulheres herdadas da literatura masculina (GILBERT; GUBAR, 2000). As obras 
publicadas não são consideradas feministas, pois a tradição patriarcal ainda está presente, mas são textos que são de alguma forma palimpsésticos - expressão usada por Gilbert e Gubar (2000) -, porque apresentam a realidade social da época na superfície do texto e inserem críticas às convenções sociais nas camadas narrativas. Nessas obras, personagens femininas têm atitudes vistas como radicais naquela época, apesar de atualmente serem julgadas como conservadoras, e condutas subversivas são relatadas rompendo padrões de gênero e questionando o status quo.

As representações de mulheres criadas pelas escritoras mencionadas são significativas porque tiveram o poder de modelar opiniões e comportamentos de leitoras e de leitores em um contexto no qual os papeis tradicionais de gênero estavam culturalmente arraigados.

Os periódicos, as revistas femininas e os romances foram armas poderosas na divulgação de novas atitudes e valores e funcionaram como fonte importante de instrução para a maioria das mulheres, para quem a escola não constituía propriamente uma opção (VASCONCELOS, 2016, p. 106).

Essa citação revela como a literatura é uma arte que tem influência sobre a construção das subjetividades dos indivíduos que a leem. Por isso, argumentamos que os romances ingleses de autoria feminina do século XIX são exemplos de tecnologia de gênero. O conceito de tecnologia de gênero foi cunhado por Lauretis (2019) a partir da discussão de tecnologias de poder de Foucault.

Foucault (2014) explica que o poder exerce domínio não apenas na forma da lei, mas, também, por meio de normas, produzindo discursos de condutas. A sociedade utiliza padrões de comportamento para vigiar as performances de gênero. Homens e mulheres controlam, através de comentários de censura ou de atitudes mais violentas, as formas como os gêneros são culturalmente performados. De acordo com Foucault (2014), a tecnologia de gênero é uma forma de poder sobre os corpos que não é visivelmente repressiva, mas existem forças atuando para o controle social. As convenções sociais "adestram" as pessoas de forma que seus corpos se tornam manipuláveis, submissos, corpos "dóceis". Nesse sentido, mulheres "aceitam" a submissão por naturalizá-la. Em contrapartida, as que discordam das limitações e obrigações impostas são reprimidas por 
olhos de outrem, que acreditam que elas precisam ser disciplinadas.

Essa concepção de poder sobre os comportamentos de gênero é usada por Lauretis (2019) para abordar as tecnologias de gênero. Para a autora, as tecnologias de gênero produzem, promovem e "implantam" representações sobre ser homem e ser mulher, as quais são propagadas por instituições (a família, a Igreja, a escola, etc.) e por discursos presentes em meios de comunicação (textos literários, jornais, revistas, televisão, cinema, rádio, etc.). Essas tecnologias tanto contribuem com a reprodução de estereótipos de mulher quanto promovem representações alternativas que desestabilizam o status quo.

O texto literário é uma dessas tecnologias de gênero que tem contribuído há séculos para moldar as subjetividades de leitoras e de leitores por meio da propagação da tradição e do fomento da (re)construção de identidades femininas. Tradição e (re)construção são aspectos inerentes ao texto literário porque sua relação com a realidade da sociedade de uma determinada época faz com que valores culturais e morais sejam reproduzidos na obra. À vista disso, obras de escritoras do século XIX apresentam a tradição de um contexto social permeada por questionamentos de personagens sobre padrões comportamentais, crenças, normas e relações sociais. A literatura de autoria feminina apresenta a dualidade vivida pelas mulheres, divididas entre padrões comportamentais e desejos de autoexpressão. Esses textos literários são "instrumentos conscientes de desmascaramento", como explica Candido (2011), no sentido de que podem levaras leitoras e os leitores a enxergarem situações de desigualdade social que antes não percebiam. Por isso, a importância histórica da atitude de escritoras que viram na produção literária uma forma de chamar a atenção para a construção cultural dos papeis de gênero centrada em interesses de poder.

\section{REPRESENTAÇÕES ALTERNATIVAS DE MULHER: PERSONAGENS FEMININAS EM ORGULHO E PRECONCEITO (1813)}

As heroínas dos romances britânicos do século XIX não quebram completamente o paradigma, pois estão dentro da cultura hegemônica (FUNCK, 2016). Ainda assim, de alguma forma, personagens subvertem padrões de gênero. Kaplan (1992) entende que essas produções literárias propagam a ideologia doméstica da época e valores patriarcais porque apresentam mulheres dedicadas ao lar, preocupadas em aprender as condutas 
femininas estabelecidas, mostram a cultura e sociedade do período. Ao mesmo tempo, essas obras revisam representações estereotipadas de mulher por incluir personagens inteligentes, impertinentes, assertivas e com energia - pois as mulheres eram vistas como frágeis e fisicamente fracas. Kaplan (1992) explica que a dualidade cultural presente nas obras existe porque a cultura feminina tinha uma relação paradoxal com a cultura gentry, de forma que parcialmente discordava do que estava posto e completamente dependia dela, no sentido financeiro e de posição social.

Essa revisão de representações de mulheres é significativa para as leitoras da época porque "nós somos as histórias que nos contam" (FUNCK, 2016, p. 418). Ao revelar formas alternativas de ser mulher, o texto literário, como uma tecnologia de gênero, promove representações diversas de sujeitos, opiniões e comportamentos sociais e discursos sobre identidades. Dessa forma, os romances podem contribuir para que mulheres construam suas subjetividades.

Na perspectiva de Vasconcelos (2016), o romance inglês de autoria feminina do século XIX teve como objetivo estimular a reforma dos costumes, seja difundindo entre as mulheres o senso de suas obrigações e virtudes, seja denunciando a sujeição, a dependência e a vulnerabilidade das mulheres. As escritoras da época criaram personagens que combinam “[...] beleza, sensibilidade, modéstia e sólidos princípios a uma inteligência viva, vigor mental, bom senso e uma dose de independência, oferecendo representações alternativas do feminino [...] (VASCONCELOS, 2016, p. 111). Tais representações são permeadas por críticas à forma como a sociedade inglesa via o papel da mulher. Jane Austen é uma dessas escritoras que inseriram no romance, de forma sutil, questionamentos sobre papéis de gênero.

A partir da concepção de Lauretis (2019) de que o gênero é produto de diferentes tecnologias sociais, ou seja, de discursos e de discussões sobre identidade, diferença e representação (HALL, 2006; WOODWARD, 2014), na vertente dos estudos culturais, fazemos uma leitura de personagens femininas do romance Orgulho e Preconceito (1813), da escritora Jane Austen. Para tanto, a identidade feminina é vista como um construto social, não como algo natural. As identidades são formadas e transformadas no interior da representação (HALL, 2006). Por isso, as imagens de mulheres promovidas pela literatura contribuem com a forma como as leitoras se veem na sociedade. 
Em Orgulho e Preconceito, no capítulo oito, as personagens Mr. Bingley, Mr. Darcy, Miss Bingley e Elizabeth Bennet conversam sobre o ideal de mulher propagado na Inglaterra no início do século XIX:

- Espanta-me a capacidade que têm as moças de se tornarem tão prendadas - disse Bingley.

- Todas as moças são prendadas! Meu caro Charles, que quer você dizer com isto?

- Sim, todas desenham mesas, forram biombos e fazem bolsas de tricô. Não conheço uma só moça que não saiba fazer todas estas coisas. E nunca ouvi mencionar o nome de uma moça pela primeira vez sem que me informassem que era muito prendada.

- A sua lista dos talentos comuns - disse Darcy — é verdadeira demais. A palavra prendada é aplicada a muitas moças somente porque sabem tricotar uma bolsa ou forrar um biombo. Mas estou longe de concordar com você no seu julgamento sobre as moças em geral. Apesar do grande número das minhas relações, não posso gabar-me de conhecer mais de meia dúzia de moças que são realmente prendadas.

— Nem eu — disse Miss Bingley.

— Nesse caso - observou Elizabeth —, deve exigir muitas qualidades para o seu ideal de mulher perfeita.

- De fato, exijo muitas qualidades.

- Oh, certamente - exclamou a sua fiel aliada. - Nenhuma mulher pode ser realmente considerada completa se não se elevar muito acima da média. Uma mulher deve conhecer bem a música, deve saber cantar, desenhar, dançar e falar as línguas modernas a fim de merecer esse qualitativo, e além disso, para não o merecer senão pela metade, é preciso que possua um certo quê em sua maneira de andar, o tom da voz e no modo de exprimir-se.

- Sim, deve possuir tudo isso - acrescentou Darcy. - E acrescentar ainda alguma coisa mais substancial: o desenvolvimento do seu espírito pela leitura intensa (AUSTEN, 2017, p. 41-42).

O diálogo revela representações culturais sobre ser mulher. Para Bingley, é uma verdade universal que todas as mulheres são prendadas, no sentido de que têm habilidades domésticas que incluem saber costurar e bordar. Na perspectiva de Darcy, um membro da aristocracia, além das habilidades domésticas, vistas como comuns às jovens da época, uma mulher precisa receber uma educação apropriada para desenvolver talentos femininos como cantar, dançar, desenhar, falar outras línguas. Miss Bingley acrescenta à lista a necessidade de um certo quê em sua maneira de andar, no tom da sua voz e no modo de exprimir-se, atitudes que, de acordo com Wells (2003), são exigidas de mulheres de classe alta em ambientes públicos. Essa personagem se identifica com tal representação de 
mulher, pois sua fala demonstra que atende completamente a tais expectativas. Miss Bingley acredita que como Elizabeth não pertence a uma classe social alta não possui todas as habilidades citadas.

As três perspectivas sobre ser mulher, as quais se complementam, mostram como o discurso propagado influencia e organiza tanto as ações dos sujeitos quanto a concepção que têm deles mesmos (HALL, 2006). Miss Bingley se vangloria por atender às normas sociais estabelecidas para as mulheres e, logo, assume o ideal de feminilidade como sua própria identidade, o defende e o reproduz como natureza feminina. $\mathrm{O}$ trecho a seguir revela como discorda da afirmação de Elizabeth de que nenhuma mulher atende a esse ideal:

- Já não me espanto de que conheça apenas seis mulheres completas, espanto-me é de que conheça alguma.

— Julga com tanta severidade o seu sexo, que duvida da possibilidade de tudo isto?

— Eu nunca vi uma tal mulher. Nunca vi tanta capacidade de aplicação, gosto e elegância reunidas numa só pessoa.

Mrs. Hurst e Miss Bingley protestaram juntas contra a injustiça contida naquela dúvida. $\mathrm{E}$ ambas declararam que conheciam muitas mulheres que correspondiam àquelas exigências (AUSTEN, 2017, p. 42).

A cena apresenta perspectivas femininas divergentes sobre a educação da mulher na época. Para Miss Bingley, Elizabeth está sendo muito injusta ao achar que as mulheres não têm capacidade de atingir as expectativas citadas. Elizabeth, no entanto, pensa que a sociedade é injusta com as mulheres ao exigir tanta dedicação para alcançar um ideal em troca de casamentos, que costumam ser arranjados, para conseguir estabilidade financeira e social.

$\mathrm{O}$ protesto da personagem Elizabeth não está diretamente relacionado às habilidades exigidas das mulheres, pois ela própria busca atendê-las por saber que é praticamente o único caminho para se conseguir um casamento rentável e ser vista como uma mulher respeitável, mas é uma crítica à hierarquização das identidades das mulheres. A estratificação social do período fazia com que apenas as mulheres de classe alta tivessem acesso a aulas de música, canto, dança e outras línguas. Dessa forma, a identidade feminina ideal estava vinculada a condições sociais e materiais (WOODWARD, 2014, p.14). Apesar de a família Bennet não ter tido condições 
financeiras para fornecer uma educação nos moldes descritos, Elizabeth acredita que isso não faz dela e de suas irmãs mulheres inferiores como pretendentes para casar.

O discurso de Miss Bingley revela como uma identidade específica está fixada como norma. Segundo Silva (2014), a normalização hierarquiza identidades e é um processo sutil de manifestação de poder. $\mathrm{O}$ autor afirma que "normalizar significa eleger uma identidade específica como o parâmetro em relação ao qual as outras identidades são avaliadas e hierarquizadas" (SILVA, 2014, p. 83).Ao posicionar-se de modo contrário ao padrão descrito por Miss Bingley, Elizabeth demonstra que percebe que sua identidade como mulher está sendo avaliada e comparada à de sua interlocutora.

\begin{abstract}
Normalizar significa atribuir a essa identidade todas as características positivas possíveis, em relação às quais as outras identidades só podem ser avaliadas de forma negativa. A identidade normal é "natural", desejável, única. A força da identidade normal é tal que ela nem sequer é vista como uma identidade, mas simplesmente como $a$ identidade. Paradoxalmente, são as outras identidades que são marcadas como tais (SILVA, 2014, p. 83).
\end{abstract}

Miss Bingley considera a imagem de mulher que descreve como $a$ identidade feminina, aceita como verdade universal e inquestionável, assim como Mrs. Hurst. Para Wells (2009), esse ideal de mulher era construído colaborativamente e sustentado tanto pelas mulheres quanto pelos homens. Como o objetivo social central é fazer com que as jovens atraiam os homens para conseguir um casamento, a competitividade para mostrarse como a mulher ideal é estimulada entre as mulheres. Em Orgulho e Preconceito, Jane Austen emprega uma linguagem irônica e estratégias de escrita para questionar esse ideal e a estratificação social da época. Elizabeth Bennet, uma personagem considerada pouco talentosa comparada a outras (Miss Bingley, Georgiana Darcy, Mary Bennet), consegue o melhor casamento no sentido financeiro e afetivo.

Ao longo da narrativa, Elizabeth recebe diversas críticas da mãe, da amiga e de conhecidos por causa de atitudes vistas como inconvenientes para uma jovem. Woodward (2014) explica que identidades diferentes do que é considerado norma podem ser vistas como "estranhas" ou "desviantes" e recebem um rótulo negativo. Para a autora, a forma como vivemos nossas identidades pode ser constrangida por discursos dominantes, pois "todo contexto ou campo cultural tem seus controles e suas expectativas, bem como seu 
‘imaginário' [...]” (WOODWARD, 2014, p. 33). A personagem Elizabeth é julgada como “estranha"quando comparada a outras jovens que atendem aos padrões sem questionamentos. Por ter atitudes inapropriadas para o contexto, é avaliada negativamente por outras mulheres, principalmente as de classe alta, como Lady Catherine:

- Sabe tocar piano e cantar, Miss Bennet?

- Um pouco.

- Então, um dia destes precisa nos dar este prazer. O nosso instrumento é dos melhores. Provavelmente superior ao... Precisa experimentá-lo qualquer dia. As suas irmãs também sabem tocar e cantar?

- Uma delas sabe.

- Por que as outras também não aprenderam? Deviam todas saber música. As irmãs Webb todas sabem tocar. E o pai delas não tinha tanto rendimento quanto o seu. Sabe desenhar?

- Não, senhora.

— O quê? Nenhuma de vocês?

- Nenhuma.

— Isto é muito curioso. Mas com certeza não tiveram oportunidade. Sua mãe devia ter levado vocês todas as primaveras para a cidade, para tomar lições.

— Minha mãe não faria objeção a isto, mas meu pai detesta Londres.

- A sua governanta foi despedida?

- Nós nunca tivemos governanta.

- Nunca tiveram governantas? Como é isto possível! Educar cinco filhas sem uma governanta! Nunca ouvi tal coisa! Sua mãe deve ter ficado escravizada à educação de vocês!

Elizabeth não pôde deixar de sorrir ao responder que este não fora o caso.

— Então quem ensinou a vocês? Quem se encarregou da sua educação? Sem uma governanta, ela deve ter sido relaxada.

- Em comparação com a de certas famílias, acredito que sim. Mas lá em casa, às meninas que quiseram aprender nunca lhes faltou meios para isto. Sempre nos encorajaram a ler e tivemos todos os professores necessários. Mas às que preferiram não estudar foi-lhes feita a vontade (AUSTEN, 2017, p. 161-162).

Na perspectiva de Lady Catherine, Elizabeth e suas irmãs deveriam ter recebido uma educação diferente para conseguir um "bom" casamento, pois suas habilidades são poucas perto de outras pretendentes que existem na região. Esse discurso é marcado pela questão da diferença, estabelecendo uma oposição entre "nós" e "vocês". Como afirma Woodward (2014), as identidades são construídas dentro de um processo de demarcação da relação com outras identidades. A cena do romance mostra como Lady Catherine vê o “outro”, o que ela não é. A relação de oposição binária produzida na situação envolve um 
desequilíbrio de poder entre as partes, o que, segundo Woodward (2014), faz com que um dos termos seja sempre mais valorizado que o outro. Na cena de Orgulho e Preconceito, Lady Catherine se coloca na posição de identidade ideal de mulher e olha para Elizabeth e suas irmãs como "desviantes".

Apesar da propagação de um ideal de mulher a partir dos discursos de personagens como Miss Bingley, Mr. Bingley, Lady Catherine e Mr. Darcy, a narrativa apresenta críticas às convenções sociais e culturais. Uma das estratégias da escritora para inserir representações alternativas de mulher é a construção de um enredo no qual as personagens que atendem ao ideal estabelecido para as mulheres são apagadas e silenciadas em diversas partes da narrativa. As expectativas sociais da época e os livros de conduta diziam que as mulheres com talentos femininos e atitudes modestas seriam recompensadas com um casamento feliz. Não é o que acontece em Orgulho e Preconceito. Elizabeth Bennet, a personagem que subverte alguns padrões comportamentais da época, é contemplada com o casamento mais bem-sucedido do romance, mesmo tendo rejeitado duas propostas de pretendentes.

Mary Bennet tem mais habilidades do que Elizabeth, sabe cantar e tocar, pratica todos os dias, mas é caracterizada com diversos defeitos que a tornam menos interessante na narrativa:

Mary não tinha talento, nem gosto. Embora a vaidade lhe tivesse dado perseverança, dera-lhe igualmente um ar pedante $e$ maneiras convencidas, coisas suficientes para obscurecer triunfos maiores do que aqueles que era capaz de alcançar (AUSTEN, 2017, p. 29).

O fato de Mary não atrair pretendentes e terminar a narrativa sem se casar pode ser visto como uma crítica aos padrões sociais. A personagem também é uma leitora voraz de livros de conduta e está sempre pronta para emitir uma opinião moralista, mas as pessoas não gostam de ouvir seus comentários pedantes. Isso revela uma crítica aos ensinamentos dos livros de conduta, pois, na perspectiva apresentada no romance, ao invés de tornar Mary virtuosa, os livros de conduta a fazem ser arrogante e imodesta.

Da mesma forma que Mary é diminuída em comparação com Elizabeth, outras personagens que poderiam atender ao ideal de mulher apresentam características que as desprestigiam. Wells (2003) afirma que uma dessas personagens poderia ser Anne de 
Bourgh, mas está debilitada por uma doença, como lamenta Lady Catherine: "Se eu jamais tivesse aprendido música, seria uma grande intérprete. E Anne também, aliás, se a saúde dela o tivesse permitido" (AUSTEN, 2017, p. 170). Outra personagem seria Miss Bingley. Caroline Bingley é essencialmente uma dama da alta sociedade, porém, apesar de todo seu talento, não consegue atrair a atenção de Mr. Darcy, mesmo se empenhando ao longo de toda a narrativa.

A irmã de Mr. Darcy, Georgiana Darcy, é uma jovem mulher elogiada desde o início da narrativa por suas habilidades. Miss Bingley afirma que "ela toca piano divinamente" (AUSTEN, 2017, p. 41), Wickham a considera bonita e muito prendada, e Darcy "louvou afetuosamente o talento de sua irmã" (AUSTEN, 2017, p. 170) diante de uma pergunta de Lady Catherine, acrescentando que ela estuda com muita constância. Apesar disso, Georgiana não se destaca em relação às outras mulheres da narrativa porque não tem a oportunidade de mostrar seus talentos. A personagem, por exemplo, não toca em público nem mesmo uma vez.Ademais, a partir da perspectiva de Elizabeth, Georgiana é apresentada como "extremamente tímida", uma pessoa que conversa pouco e em "simples monossílabos" (AUSTEN, 2017, p. 248).

Essas personagens que poderiam atender ao ideal de feminilidade têm falhas de caráter que as impedem de serem vistas como modelos dentro da narrativa, fazendo com que os refletores estejam voltados para Elizabeth Bennet. A escritora Jane Austen usou uma linguagem irônica e estratégias de escrita para mostrar que o padrão idealizado de mulher não existe na realidade, pelo menos não neste romance. $\mathrm{O}$ que sustenta a opinião de Elizabeth quando diz: "Eu nunca vi uma tal mulher. Nunca vi tanta capacidade de aplicação, gosto e elegância reunidas numa só pessoa” (AUSTEN, 2017, p. 42).

A narrativa do romance também utiliza outra estratégia de escrita para expor os estereótipos de feminilidade do período, como a duplicação de personagens femininas (POOVEY, 1984), na qual uma personagem que é o oposto da heroína é inserida para abordar atitudes consideradas completamente inapropriadas para as mulheres. Em Orgulho e Preconceito, Lydia Bennet faz esse papel. A vivacidade, ousadia e atitudes consideradas não femininas de Elizabeth são apresentadas de forma positiva na narrativa em oposição ao comportamento rebelde, impertinente, despreocupado de Lydia. Para Auerbach (2004), Jane Austen constrói duas irmãs Bennets impetuosas, uma para ser admirada e outra para 
ser censurada. A desaprovação recai sobre Lydia, a personagem que subverte diversos padrões de gênero na narrativa, porque Elizabeth, em comparação, ainda atende às expectativas sociais.

Lydia Bennet, portanto, é também um recurso narrativo empregado para questionar e tentar desestabilizar estereótipos de feminilidade. A personagem não é modesta, afirma publicamente seu interesse por bailes e sua atração por homens de uniformes vermelhos, os oficiais. A chegada de um regimento da milícia na região aumenta a frequência de visitas de Lydia à casa da tia que reside na cidade:

Cada dia acrescentava novas informações ao que [Lydia e Kitty] já sabiam acerca dos nomes dos oficiais e das suas relações. O lugar onde esses oficiais residiam não permaneceu muito tempo em segredo. E, finalmente, elas começaram a travar conhecimento com os próprios oficiais (AUSTEN, 2017, p. 32-33).

Lydia e Kitty Bennettêm uma atitude desviante da educação moral dirigida às mulheres, registrada nos livros de conduta, e que poderia arruinar a reputação de uma moça e de toda sua família.

Elizabeth Bennet é quem alerta o pai a respeito do comportamento socialmente inadequado da irmã dizendo: "a nossa reputação deve sofrer necessariamente com a leviandade de Lydia, a imprudência e o desdém de toda restrição que marcam o seu caráter." (AUSTEN, 2017, p.224). A personagem afirma que Lydia age como uma namoradeira e que as pessoas da região começarão a comentar sobre sua falta de modéstia. Diante disso, Elizabeth é julgada positivamente por entender que existem restrições para as mulheres, as quais não devem ser excedidas, e consegue casar-se com um homem desejado por muitas mulheres, por ser rico e íntegro. A virtude da personagem é mantida do início ao fim da narrativa e a faz ter um final feliz como mulher ao conseguir um casamento tranquilo.

Lydia Bennet, ao contrário, não se preocupa com as convenções sociais, as rejeita em diversos momentos, age como quer para conseguir um marido, seu principal objetivo. A fuga da personagem com um oficial atrai o julgamento negativo da sociedade para a família Bennet,que precisa tentar manter uma reputação respeitável oficializando o casamento. Lydia realiza o sonho de se casar, no entanto "a afeição de Wickham por 
Lydia em breve se transformou em indiferença. A de Lydia resistiu por mais algum tempo" (AUSTEN, 2017, p. 364). O relacionamento não é afortunado no sentido afetivo e financeiro. A personagem, exemplo de desconstrução do ideal de feminilidade, é punida no romance, produzido em um contexto de rígidas convenções sociais, porque fere os preceitos da virtude feminina.

Personagens como Elizabeth Bennet e Lydia Bennet, que sugeriam a quebra dos padrões de gênero culturalmente arraigados, apresentavam para as leitoras e leitores do romance representações alternativas de mulheres. Tais representações eram relevantes para modificar as ideias de gênero estabelecidas, ainda que a passos lentos, porque muitas escritoras desse período não abordavam essa questão de maneira explícita com medo de serem censuradas. Woodward (2014) explica que os significados produzidos pelas representações dão sentido à nossa experiência e àquilo que somos. Portanto, a leitura de Orgulho e Preconceito pode ter sugerido alternativas sobre ser mulher diferentes das mostradas por livros de conduta, por exemplo, e feito com que as imagens das personagens passassem a ser identidades desejadas pelas leitoras. Para Woodward (2014), a representação, como um processo cultural, pode dar respostas para questões como “Quem eu sou?", “O que eu poderia ser?", "Quem eu quero ser?" e o fato de existir personagens que questionam de alguma forma o status quo insere novas formas de ser mulher no imaginário social.

Elizabeth Bennet desconstruiu expectativas sociais de gênero e contribuiu para a (re)construção de imagens de mulheres da época porque suas atitudes, diferentemente das de Lydia, são socialmente aceitáveis. Apesar de impertinente e, em alguns momentos, vista como não feminina, Elizabeth não fere convenções morais sobre a virtude de uma mulher.A personagem se recusou a casar para garantir estabilidade financeira. Disse não à proposta de Mr. Collins, ainda que isso significasse perder a propriedade da família, visto que ele era o parente do sexo masculino mais próximo em linha colateral na família e considerado o herdeiro porque Mr. Bennet não tinha filhos e a lei do direito comum não permitia que mulheres recebessem herança. Também disse não a Mr. Darcy em um primeiro momento. As duas recusas ocorreram porque ambos tinham falhas de caráter que não lhe agradavam. Para a época, essa atitude era subversiva, pois o objetivo primordial das mulheres de classes média e alta, devido ao contexto anteriormente apresentado, era 
conseguir um casamento. Após Elizabeth aceitar um segundo pedido de casamento de Mr.

Darcy, brinca com a situação e pergunta o que o levou a se apaixonar:

- Minha beleza você a tinha negado desde o princípio. E quanto às minhas maneiras, meu comportamento para com você sempre beirou a falta de educação. E quase sempre, quando me dirigia a você, era com o intuito de feri-lo. Agora seja sincero: foi por causa da minha impertinência que me admirou?

- Pela vivacidade da sua inteligência, sim.

- É melhor chamar logo de impertinência. Era pouco menos. O fato é que estava farto de amabilidades, deferências e atenções. Sentia-se enojado com as mulheres que falavam, agiam e pensavam com o único fito de conquistá-lo. Despertei a sua atenção porque era tão diferente delas. Se você não fosse realmente bom, teria me odiado. Mas apesar do trabalho que teve para disfarçar os seus sentimentos, estes sempre foram nobres e justos. E no seu coração sempre desprezou as pessoas que o cortejavam tão assiduamente. Aí está: já lhe poupei o trabalho de uma explicação; e realmente, pensando bem, acho a minha hipótese muito razoável. Para falar a verdade, não conhecia nenhuma boa qualidade em mim. Mas ninguém pensa nisto quando se apaixona (AUSTEN, 2017, p. 357).

Esse diálogo contradiz os padrões de gênero da época, os ensinamentos dos livros de conduta e as expectativas sociais sobre como as mulheres deveriam se comportar. Mr. Darcy afirma ter sido atraído pela inteligência de Elizabeth, não por sua beleza, talentos, habilidades domésticas. O conselho de livros de conduta para esconder a razão dos homens não foi seguido por Elizabeth, e exatamente por esse motivo ela foi escolhida como esposa. Além disso, o diálogo revela que a personagem é impertinente, não é modesta, nem frágil ou dócil, age de modo considerado inapropriado para as mulheres. Essa representação de mulher no romance é um modelo para as leitoras da época que desestabiliza, ainda que sutilmente, o ideal hegemônico de mulher.

\section{CONSIDERAÇÕES FINAIS}

O gênero é produto de diferentes tecnologias sociais (LAURETIS, 2019). A literatura é uma dessas tecnologias que produz discursos e sentidos sobre o que é ser uma mulher. Como a representação de gênero é uma construção social que tem poder sobre as atitudes e opiniões dos sujeitos, a forma como mulheres são representadas em romances pode impactar sobre as leitoras. Por isso, os discursos propagados pelo romance Orgulho e 
Preconceito podem ter contribuído para que leitoras repensassem suas próprias identidades naquele momento histórico marcado por normas comportamentais rígidas.

As identidades são criadas a partir de relações sociais e de poder. Enquanto a sociedade do período tentava cultivar as virtudes femininas por meio de obras como livros de conduta, escritoras viram na literatura a possibilidade de educarem mulheres para reavaliarem o status quo. Elizabeth Bennet, apesar de seus desvios dos padrões comportamentais, consegue o casamento mais afetuoso e o marido com maior riqueza de todas as obras da escritora Jane Austen. É um exemplo de como a escritora utiliza o poder da representação para (re)construir as subjetividades de suas leitoras.

Como uma forma de autoexpressão, Jane Austen utilizou o texto literário para mostrar que mulheres que não seguem os padrões sociais não são "monstros", pois a própria escritora era vista como "desviante" porque nunca se casou ou teve filhos e, além de tudo, ousou publicar romances. Apesar de julgada como inadequada, o ato de escrita de Jane Austen convidou outras mulheres a publicarem seus textos e ajudou a consolidar a carreira literária para as mulheres.

\section{REFERÊNCIAS}

AUERBACH, E. Searching for Jane Auten. London: University of Wisconsin Press, 2004.

AUSTEN, J. Orgulho e Preconceito. Trad. Lúcio Cardoso. 20. ed. Rio de janeiro: Nova Fronteira, 2017.

CAMPOS, M. C. C. Gênero. In: JOBIM, J. L. (Org.). Palavras da crítica: tendências e conceitos no estudo da literatura. Rio de Janeiro: Imago, 1992, p. 11-125.

CANDIDO, A. O direito à literatura. In: CANDIDO, A. Vários escritos. Rio de Janeiro: Ouro sobre azul, 2011, p. 171-193.

FOUCAULT, M. Vigiar e punir: nascimento da prisão. Trad. Raquel Ramalhete. 42.ed. Petrópolis, RJ: Vozes, 2014.

FUNCK, S. B. Crítica literária feminista: uma trajetória. Florianópolis: Editora Insular, 2016.

GILBERT, S. M.; GUBAR, S. The madwoman in the attic: the woman writer and the nineteenth-century literary imagination. New Haven e Londres: Yale UP, 2000. 
HALL, S. A identidade cultural na pós-modernidade. Trad. Tomaz Tadeu da Silva, Guaracira Lopes Louro. 11.ed. Rio de Janeiro: DP\&A, 2006.

KAPLAN, D. Jane Austen among women. Baltimore, Maryland: Johns Hopkins Press, 1992.

LAURETIS, T. A tecnologia de gênero. In: HOLLANDA, H. B. (Org.). Pensamento feminista: conceitos fundamentais. Rio de Janeiro: Bazar do Tempo, 2019.

POOVEY, M. The proper lady and the woman writer: ideology as style in the works of Mary Wollstonecraft, Mary Shelley, and Jane Austen. Chicago and London: The University of Chicago Press, 1984.

SILVA, T. T. A produção social da identidade e da diferença. In: SILVA, T. T. (Org.). Identidade e diferença: a perspectiva dos estudos culturais. Trad. Tomaz Tadeu da Silva. 15.ed. Petrópolis, RJ: Vozes, 2014, p. 73-102.

SHOWALTER, E. A literature of their own: British women writers, from Charlotte Brontë to Doris Lessing. London: Virago Press, 1977.

TEACHMAN, D. Understanding Pride and Prejudice: a student casebook to issues, sources, and historical documents. Greenwood Press, 1997.

VASCONCELOS, S. G. Dez lições sobre o romance inglês do século XVIII. São Paulo: Boitempo, 2016.

WELLS, J. Accomplished women: gender, artistry, and authorship in nineteenth-century England. Tese (doutorado) - Yale University, Faculty of the Graduate School, 2003.

WELLS, J. Filming the "really accomplished" woman: performance and gender in recent adaptations of Pride and Prejudice. In: ENGEL, L. (Ed.). The public's open to us all: essays on women and performance in eighteenth-century England. Cambridge Scholars Publishing: Newcastle, 2009, p. 300-322.

WOODWARD, K. Identidade e diferença: uma introdução teórica e conceitual. In: SILVA, T. T. (Org.). Identidade e diferença: a perspectiva dos estudos culturais. Trad. Tomaz Tadeu da Silva. 15.ed. Petrópolis, RJ: Vozes, 2014, p. 7-72.

WOLLSTONECRAFT, M. Reivindicação dos direitos da mulher. Trad. Ivania Pocinho Motta. São Paulo: Boitempo, 2016.

WOOLF, V. Um teto todo seu. Trad. Bia Nunes de Sousa, Glauco Mattoso. São Paulo: Tordesilhas, 2014. 